\title{
KEEFEKTIFAN MODEL COOPERATIVE LEARNING TIPE TALKING STICK TERHADAP HASIL BELAJAR MATEMATIKA
}

\author{
Ardhita Dian Aslami ${ }^{1}$, Moh. Aniq KHB ${ }^{2}$, Diana Endah $\mathrm{H}^{3}$ \\ 1,2,3 Jurusan PGSD Fakultas IImu Pendidikan Universitas PGRI Semarang \\ e-mail:ardhitadian@gmail.com
}

\begin{abstract}
ABSTRAK
Penelitian ini bertujuan untuk mengetahui keefektifan model Cooperative Learning tipe Talking Stick terhadap mata pelajaran matematika siswa kelas II SD Negerti Tambakrejo 02 Semarang.. Jenis penelitian ini menggunakan penelitian kuantitatif dengan metode pre-experimental design tipe one group pretest-posttest (tes awal-tes akhir kelompok tunggal). Populasi dari penelitian ini adalah siswa kelas II SD Negeri Tambakrejo 01 Semarang yang berjumlah 26 orang. Data yang dikumpulkan dalam penelitian ini diperoleh dari hasil wawancara, dokumentasi, tes, dan observasi. Data yang diperoleh yaitu rata-rata nilai posttest analisis uji $t$ di peroleh $t$ hitung $>t$ tabel yaitu 5,535 $>2,06$ sehingga $\mathrm{H}_{0}$ di tolak dan Ha diterima, dari pengujian ketuntasan belajar individu nilai diatas KKM (65.00) seluruh peserta didik berjumlah 26 siswa lulus KKM dengan nilai tuntas dari KKM, dan dari pengujian ketuntasan belajar klasikal hasil belajar peserta didik secara keseluruhan mencapai persentase $100 \%$. Meningkatnya hasil belajar peserta didik sebelum dan sesudah di beri perlakuan berupa pemberian model Cooperative Learning tipe Talking Stick yang ditunjukan dengan hasil nilai rata-rata posttest yang meningkat.
\end{abstract}

Kata Kunci : Model Cooperative Learning, Talking Stick, Mata Pelajaran Matematika

\begin{abstract}
This study aims to determine the effectiveness of the Talking Stick Cooperative Learning model of mathematics subjects in class II SD Negerti Tambakrejo 02 Semarang. This type of research us es quantitative research with the pre-experimental design type one group pretest-posttest (initial-final test) single group). The population of this research is the second grade students of SD Negeri Tambakrejo 01 Semarang, amounting to 26 people. Data collected in this study were obtained from interviews, documentation, tests and observations. The data obtained is the average value of the posttest analysis of the $t$ test obtained $t$ count $>t$ table is 5.535> 2.06 so that $\mathrm{HO}$ is rejected and $\mathrm{Ha}$ is accepted, from the individual learning completeness test values above the KKM (65.00) all students total 26 students graduated KKM with complete marks from KKM, and from classical learning completeness testing the learning outcomes of students as a whole reached a percentage of $100 \%$. The increase in student learning outcomes before and after treatment is given in the form of giving the Cooperative Learning model the type of Talking Stick which is shown by the results of the posttest average value increasing.
\end{abstract}

Keywords : Cooperative Learning Models, Talking Sticks, Mathematics Subjects 


\section{Pendahuluan}

Pendidikan adalah sebagai usaha sadar atau proses pembelajaran bagi peserat didik untuk dapat mengerti, paham, membuat manusia lebih kritis dalam berfikir, dan untuk kemajuan taraf hidup yang lebih baik. Pendidikan nasional adalah usaha sadar dan terencana untuk mewujudkan suasana belajar dan proses pembelajaran agar peserta didik secara aktif mengembangkan potensi dirinya untuk memiliki kekuatan spiritual keagamaan, pengendalian diri, kepribadian, kecerdasan, akhlak mulia serta ketrampilan yang diperlukan dirinya, masyarakat, bangsa dan negara. (UU.No 20 Tahun 2003).

Menurut Soegeng (2015 : 76), penyelenggaraan pendidikan di Indonesia ada tiga jalur pendidikan yang disebut Tripusat Pendidikan yaitu: (1) pendidikan informal, (2) pendidikan formal, (3) pendidikan nonformal. Pendidikan formal atau pendidikan sekolah merupakan jalur pendidikan yang diselenggarakan di sekolah merupakan jalur pendidikan yang diselenggarakan di sekolah melelui kegiatan belajar mengajar yang berjenjang dan berkesinambungan, salah satunya adalah sekolah dasar.

Pembelajaran matematika diharapkan mampu menciptakan paradigma siswa terhadap kegunaan matematika dalam kehidupan. Namun tidak mudah untuk dapat menumbuhkan sikap menghargai kegunaan matematika dalam kehidupan, sebab konsep matematika disajikan dalam bentuk abstrak. Soedjadi (dalam Muhsetyo, dkk., 2008: 1.2) mengemukakan bahwa keabstrakan matematika karena objek dasarnya abstrak, yaitu fakta, konsep, operasi dan prinsip. Ciri keabstrakan matematika beserta ciri lainnya yang tidak sederhana, menyebabkan matematika tidak mudah untuk dipelajari, dan pada akhirnya banyak siswa yang kurang tertarik terhadap matematika.

Berdasarkan definisi di atas sesuai dengan perkembangan zaman, guru sangat berperan penting dalam memberi pengetahuan dan di tuntut untuk bisa mengikuti perkembangan zaman pada era globalisasi saat ini, pada perkembangan zaman saat ini guru dituntut preofesional, mampu menciptakan pembelajaran yang aktif, kreatif, inovatif, dan menyenangkan. Dengan demikian sangat di butuhkan guru salah satunya yang kreatif agar bisa menciptakan pembelajaran yang menyenangkan agar bisa mencapai tujuan pendidikan yang telah di rancang. Untuk mencapai keberhasilan tujuan pembelajaran yang sudah direncanakan, pemilihan berbagai model yang tepat merupakan suatu hal yang utama.

Berdasarkan hasil wawancara dengan ibu Ligar S.Pd.SD guru kelas II di SD Negeri Tambakrejo 01 Semarang ada beberapa kendala yang menghambat proses pembelajaran seperti penggunaan model pembelajaran belum ada sehingga siswa kurang memahami materi yang diberikan oaleh guru, khususnya pada pembelajaran matematika guru hanya mengajar dengan cara-cara yang sudah ada dan belum menggunakan model. Terbukti pada hasil Ulangan Harian hanya ada 9 siswa yang tuntas sedangkan 17 siswa lainya masih berada dibawah KKM itu menandakan bahwa hanya $25 \%$ siswa yang tuntas sedangkan pada nilai Ulangan Tengah Semester (UTS) hanya 10 siswa yang tuntas 16 siswa lainya masih di bawah KKM itu menandakan hanya $28 \%$ siswa yang tuntas. Dari segi siswa sendiri mereka masih merasa kurang paham dengan konsep pelajaran matematika yang menurut siswa matematika merupakan mata pelajaran yang sulit sehingga menyebabkan hasil belajar matematika siswa menjadi kurang maksimal, minat siswa kurang dalam kegiatan belajar matematika karena terkadang siswa merasa bosan dengan proses pembelajaran yang biasanya hanya mendengarkan ceramah dari guru, siswa merasa kesulitan untuk mengemukakan pendapat karena merasa takut jika salah dalam menjawab, dan juga interaksi antara guru dengan siswa ketika pembelajaran kurang maksimal dikarenakan guru masih merasa kesulitan menjelaskan kepada siswa. Oleh karena itu, peneliti bermaksud akan melakukan penelitian menggunakan model pembelajaran yang memacu siswa untuk untuk aktif sehingga dapat meningkatkan hasil belajar, yaitu dengan model Cooperative Learning tipe Talking Stick.

Menurut Sumantri (2015: 154) bentuk- bentuk karakteristik siswa SD yaitu (1) senang bermain, (2) senang bergerak, (3) anak senang bekerja kelompok, (4) senang merasakan atau melakukan/memperagakan sesuatu secara langsung. Dengan hal tersebut model yang 
bisa digunakan untuk mengatasi pembelajaran matematika kelas II, yaitu dengan menggunakan model Talking Stick. Suprijono (2014: 109) mengungkapkan bahwa salah satu kelebihan model Talking Stick adalah mendorong siswa untuk berani mengemukakan pendapat. Huda (2014b: 225) menyatakan bahwa model Talking Stick cocok digunakan di semua kelas dan semua tingkatan umur. Model pembelajaran Talking Stick bermanfaat untuk menguji kesiapan siswa, melatih keterampilan membaca dan memahami materi pelajaran dengan cepat, serta mengajak siswa siap dalam situasi apapun.

Menurut Sumantri ( 2007:129) pelaksanaan model pembelajaran Talking Stick yaitu guru membentuk kelompok, kemudian menyuruh siswa mengerjakan tugas kelompok dan mempelajari materi bersama kelompoknya. Setelah siswa selesai mempelajari materi, guru menyuruh siswa untuk menutup buku. Guru mengambil tongkat dan memberikan tongkat kepada salah satu siswa. Tongkat tersebut diputar ke seluruh siswa dengan sambil menyanyikan lagu agar siswa tidak merasa tegang. Siswa yang memegang tongkat harus menjawab pertanyaan dari guru. Model pembelajaran Talking Stick termasuk salah satu model pembelajaran Kooperatif.

Menurut Trianto (2007: 41), dengan model pembelajaran Kooperatif, siswa akan lebih mudah menemukan dan memahami konsep yang sulit apabila mereka saling berdiskusi dengan temannya. Pembelajaran Kooperatif merupakan suatu praktik pedagogis. Pembelajaran Kooperatif dapat meningkatkan proses pembelajaran, gaya belajar tingkat tinggi, perilaku sosial, dan kepedulian terhadap siswa lain yang memiliki latar belakang berbeda (Huda, 2014a: 27). Siswa akan memperoleh berbagai manfaat apabila guru menerapkan pembelajaran Kooperatif.

\section{Metode}

Pada penelitian ini, penulis melakukan penelitian kuantitatif dengan menggunakan metode pre-experimental design tipe one group pretest-posttest (tes awal-tes akhir kelompok tunggal).

Arikunto (2010:124) mengatakan, bahwa one group pretest-posttest design adalah kegiatan penelitian yang memberikan tes awal (pretest) sebelum diberikan perlakuan, setelah diberikan perlakuan barulah memberikan tes akhir (posttest).

Setelah melihat pengertian tersebut dapat ditarik simpulan bahwa hasil perla-kuan dapat diketahui lebih akurat karena dapat membandingkan dengan keadaan sebelum diberikan perlakuan. Penggunaan desain ini disesuaikan dengan tujuan yang hendak dicapai, yaitu untuk mengetahui kemampuan pada mata pelajaran matematika sebelum dan sesudah dan sesudah diberikan perlakuan.

Rancangan one group pretest-posttest design ini terdiri atas satu kelompok yang telah ditentukan. Di dalam rancangan ini dilakukan tes sebanyak dua kali, yaitu sebelum diberi perlakuan disebut prates dan sesudah perlakuan disebut pas-cates. Adapun pola penelitian metode one group pretest-posttest design menurut Sugiyono (2013:75) sebagai berikut:

\section{$\mathrm{O}_{1} \times \mathrm{O}_{\text {, }}$}

Keterangan :

$\mathrm{O}_{1}=$ nilai prates (sebelum perlakuan)

$\mathrm{X}=$ model pembelajaran talking stick

$\mathrm{O}_{2}=$ nilai pascates (setelah diberi perlakuan) 
Pada design ini tes yang dilakukan sebanyak dua kali, yaitu sebelum dan se-sudah diberikan perlakuan eksperimen. Tes yang dilakukan sebelum mendapatkan perlakuan disebut prates. Prates diberikan pada kelas eksperimen (O1). Setelah di-lakukan prates, penulis memberikan perlakuan berupa pembelajaran dengan menggunakan model talking stick $(\mathrm{X})$, pada tahap akhir penulis memberikan pascates $(\mathrm{O} 2)$.

\section{Hasil dan Pembahasan}

Pelaksanaan penelitian ini diberikan lembar soal Pretest di awal pembelajaran untuk mengetahui hasil belajar siswa sebelum diberikan perlakuan. Peneliti memberikan perlakuan (treatment) dengan menggunakan sebanyak 3 kali pembelajaran menggunakan model Talking Stick untuk meningkatkan hasil belajar matematika materi mengenal satuan waktu. Dalam setiap pembelajaran selalu diberikan lembar evaluasi untuk mengetahui tingkat pemahaman materi siswa saat diberi perlakuan pada setiap pembelajaran. Setelah diberikan perlakuan dengan menggunakan model Talking Stick sebanyak 3 kali pembelajaran, peneliti memberikan lembar soal posttest untuk mengetahui peningkatan hasil belajar.

Selain nilai pretest dan posttest yang akan digunakan sebagai nilai aspek kognitif, terdapat pula penilaian ketrampilan melalui lembar observasi sebagai penilaian psikomotorik, pelaksanaan pembelajaran dengan menggunakan model Cooperative Learning tipe Talking Stick berjalan dengan baik. Dalam kegiatan pertemuan ke-1 menggunakan Cooperative Learning tipe Talking Stick menunjukkan rata-rata nilai keterampilan kerapihan penulisan 76,47 , siswa mampu menuliskan waktu yang ditentukan 80,00 , ketepatan memilih kosakata 79,89 , dan siswa mampu menggambar waktu yang ditentukan 78,73. Dalam ranah keterampilan rata-rata siswa telah mencapai kriteria ketuntasan minimal (KKM).

Menurut Fudyartanto dalam Baharuddin dan Wahyuni (2015: 15) Dalam kamus besar bahsa indonesia, secara etismologis belajar memiliki arti "berusaha memperoleh kepandaian atau ilmu". Definisi ini memiliki pengertian bahwa belajar adalah kegiatan untuk mencapai kepandaian atau ilmu. Di sini, usaha untuk mencapai kepandaian atau ilmu merupakan usaha manusia untuk memenuhi kebutuhannya mendapat ilmu atau kepandaian yang belum dipunyai sebelumnya. Sehingga dengan belajar itu manusia menjadi tahu, memahami, mengerti, dapat melaksanakan dan memiliki tentang sesuatu.

Berdasarkan teori yang dipaparkan diatas, sesuai dengan hasil penelitian mengenai keefektifan model Cooperatif Learning tipe Talking Stick terhadap hasil belajar matematika siswa kelas II SD Negeri Tambakrejo 01 Semarang membuat siswa tertarik dan memperhatikan apa yang disampaikan penelitian sehingga belajar siswa mengalami peningkatan hal ini sejalan dengan teori Bell-Gredler dalam Baharuddin dan Wahyuni (2015: 13-14) berpendapat kemampuan manusia untuk belajar merupakan karakteristik penting yang membedakan manusia dengan makhluk hidup lainnya. Belajar mempunyai keuntungan baik bagi individu maupun bagi masyarakat. Bagi individu, kemampuan untuk belajar secara terus-menerus akan memberi kontribusi terhadap pengembagan kualitas hidupnya.

Berdasarkan hasil uji tes awal atau pretest menunjukan bahwa sebagian peserta didik mendapatkan nilai belum mencapai KKM yaitu 65,00 yang telah ditentukan oleh sekolah. Pada hasil nilai pretest terdapat terdapat 13 dari 26 peserta didik dinyatakan tidak tuntas dan 13 dari 16 peserta didik dinyatakan lulus atau tuntas. Hasil Posttest menunjukkan bahwa nilai peserta didik setelah di berikan perlakuan menjadi lebih baik dengan rata-rata nilai yang memuaskan terdapat yaitu seluruh peserta didik berjumlah 26 tuntas 100.. Dengan nilai Posttest tersebut, menunjukkan bahwa model Cooperative Learning tipe Talking Stick memberikan keefektifan yang baik terhadap hasil belaja kognitif siswa pada materi mengenal satuan waktu, perbedaan nilai menunjukkan adanya perbedaan antara pembelajaran dengan sebelum diberikan perlakuan dan sesuah diberikan perlakuan menerapkan model Cooperative Learning tipe Talking Stick. Berdasarkan hasil uji $t$ di peroleh $t_{\text {hitung }}>t_{\text {tabel }}$ atau 5,535 >2,060 sehingga $\mathrm{H}_{0}$ ditolak dan $\mathrm{H}_{\mathrm{a}}$ diterima, dari pengujian ketuntasan belajar individu nilai diatas KKM (65.00) sebanyak 26 peserta didik tuntas nilai KKM, dan dari pengujian ketuntasan belajar klasikal hasil belajar peserta didik secara keseluruhan mencapai 
presentase $100 \%$. Dapat disimpulkan bahwa model pembelajaran Cooperative Learning tipe Talking Stick efektif terhadap hasil belajar peserta didik pada mata pelajaran matematika materi mengenal satuan waktu di kelas II SD Negeri Tambakrejo 01 Semarang.

Hasil perhitungan diatas membuktikan bahwa penerpan model Cooperative Learning tipe Talking Stick efektif digunakan untuk meningkatkan hasil belajar kognitif siswa kelas ॥ SD Negeri Tambakrejo 01 Semarang pada mata pelajaran matematika materi mengenal satuan waktu dikarenakan peserta didik sangat aktif dalam mengikuti semua proses pembelajaran, peserta didik termotivasi, perhatian peserta didik lebih terpusatkan pada saat pembelajaran. Peserta didik mendapatkan tantangan tersendiri dalam pembelajran adanya umpan balik yang baik, dan peserta dapat menerima perbedaan yang ada. Berikut adalah data hasil nilai posttest dan pretest sebagai berikut.

Tabel 1. Hasil Pretest dan Posttest Kelas II SD Negeri Tambakrejo 01 Semarang

\begin{tabular}{lcc}
\hline \multicolumn{1}{c}{ Keterangan } & Pretest & Posttest \\
\hline Nilai terendah & 40 & 65 \\
Nilai tertinggi & 85 & 100 \\
Tuntas & 13 & 26 \\
Tidak tuntas & 13 & 0 \\
\hline \multicolumn{1}{c}{ Rata-rata } & $\mathbf{6 2 , 8}$ & $\mathbf{8 0 , 7}$ \\
\hline
\end{tabular}

Berdasarkan hasil pembelajaran, penilaian ranah keterampilan siswa selama proses pembelajaran mengenal satuan waktu pada pertemuan 1 menunjukan nilai rata- rata kerapihan penulisan 76,47, mampu menuliskan waktu yang ditentukan 80,00, ketepatan memilih kosakata 79,89 dan mampu menggambar waktu yang ditentukan 78,73 . Berikut adalah tabel hasil penilaian ranah keterampilan :

Tabel 2. Penilaian Ranah Keterampilan

\begin{tabular}{lc}
\hline \multicolumn{1}{c}{ Penilaian Keterampilan } & Rata-rata \\
\hline Kerapihan penulisan & 76,47 \\
Mampu menuliskan waktu yang ditentukan & 80,00 \\
Ketepatan memilih kosakata & 79,89 \\
Mampu menggambar waktu yang ditentukan & 78,73 \\
\hline
\end{tabular}

\section{Simpulan dan Saran}

Berdasarkan hasil penelitian dan pembahasan dalam penelitian ini dapat disimpulkan bahwa penerapan model Cooperative Learning tipe Talking Stick efektif digunakan untuk meningkatkan hasil belajar kognitif peserta didik, pada mata pelajaran matematika materi mengenal satuan di kelas II SD Negeri 01 Semarang. Hal ini dibuktikan dengan hasil ratarata nilai posttest analisis uji $t$ di peroleh $t$ hitung $>t$ tabel yaitu 5,535 $>2,06$ sehingga $\mathrm{H}_{0}$ di tolak dan Ha diterima, dari pengujian ketuntasan belajar individu nilai diatas KKM (65.00) seluruh peserta didik berjumlah 26 siswa lulus KKM dengan nilai tuntas dari KKM, dan dari pengujian ketuntasan belajar klasikal hasil belajar peserta didik secara keseluruhan mencapai persentase $100 \%$. Meningkatnya hasil belajar peserta didik sebelum dan sesudah di beri perlakuan berupa pemberian model Cooperative Learning tipe Talking Stick yang ditunjukan dengan hasil nilai rata-rata posttest yang meningkat.

Berdasarkan hasil penelitian pada peserta didik kelas II SD Negeri Tambakrejo 01 Semarang semester genap tahun 2019/2020, maka saran yang dapat diajukan adalah sebagai berikut: 1) Model pembelajaran Cooperative Learning tipe Talking Stick dapat dijadikan salah satu media pembelajaran alternatif agar proses pembelajaran bervariasi dan menyenangkan yang dapat digunakan untuk kelas tinggi maupun kelas rendah; 2) Pembelajaran dengan menggunakan model Cooperative Learning tipe Talking Stick dapat 
dimodifikasi tidak hanya menggunakan satu tongkat namun dua tongkat dan dari dua arah pula agar pembelajaran semakin menyenangkan; 3) Saat pembelajaran menggunakan model Cooperative Learning tipe Talking Stick guru harus bisa mengatur siswa sebaik mungkin agar kelas tetap kondusif.

\section{Daftar Pustaka}

Agus, Suprijono. 2014.Cooperative Learning. Yogyakarta: Pustaka Pelajar.

Ahmad, Susanto. 2013. Teori Belajar dan Pembelajaran di Sekolah Dasar. Jakarta: Kencana Prenadamedia Group

Arifin, Zainal. 2016. Evaluasi Pembelajaran (Prinsip, Teknik, dan Posdur), Cetakan Kedelapan, Jakarta: Rosda Karya.

Arikunto, S. 2010. Prosedur Penelitian Suatu Pendekatan Praktik. Jakarta: Rineka Cipta.

Arikunto,Suharsimi.2016. Dasar-Dasar Evaluasi Pendidikan. Jakarta: PT Bumi Aksara

Daryanto.2014. Pembelajaran Tematik, Terpadu, Terintegrasi (Kurikulum 2013). Yogyakarta : GAVA MEDIA.

Darmastuti,Lungid (2015) Keefektifan Model Talking Stick dalam Pembelajaran Uang Dan Kegunaannya Pada Siswa Kelas III SD Negeri Randugunting 2 Kota. Digilib Unnes, $3(2)$

David W. Johnson, Roger T. Johnson, and Mary Beth Stanne. 2000. Cooperative Learning Methods: A Meta-Analysis. Minnesota : University of Minnesota

Depdiknas. 2003. Undang-Undang Nomor 20 Tahun 2003 Tentang Sistem Pendidikan Nasional. Jakarta: Depdiknas.

Deutsch M., 1949, "A Theory of Co-operation and Competition”, Human Relations, 2, 129-151.

Doob, L. W. (1947). The behaviour of attitudes. Psychological Review, 54(1), 135-156.

Hajar, lbnu.2013. Panduan lengkap kurikulum tematik untuk SD/Ml. Yogyakarta; DIVA Press.

Hamalik, Oemar.2014. Psikologi Belajar \& Mengajar.Bandung: Sinar Baru Algensindo.

Huda, Miftahul. 2014. Model-model Pengajaran dan Pembelajaran. Yogyakarta: Pustaka Pelajar

Huda, Miftahul. 2016. Cooperative Learning metode, teknik struktur, dan model. Yogyakarta : Pustaka Pelajar.

Kunandar. 2011. Penelitian Tindakan Kelas. Jakarta: Rajawali Pers.

Kurnia, Ingridwati, dkk. 2007. Perkembangan Belajar Peserta Didik: Direktorat Jenderal Pendidikan Tinggi Departemen Pendidikan Nasional. 
Kuriniawan, Nursidi. (2011). "Karakteristik don Kebutuhan Pendidikan Anak usia Sekolah Dasar", Jurnal dgrils, 1(3)

Mirajati, Desi. (2010). Penerapan Model Pembelajaran Talking Stick dengan Teknik Story Telling dalam Meningkatkan Kemampuan Menceritakan Pengalaman Orang Lain Siswa Kelas III SD Negeri Karangrejo Selomerto Wonosono I. Digilib Unnes, 36(1)

Nurtiningsih, Wahyuni. (2017). Penerapan Model Cooperative Learning tipe Talking Stick Untuk meningkatkan Aktivitas dan Hasil belajar Matematika Siswa kelas V SD Negeri 1 Simbarwaringin. Jurnal Unila, 3(1)

Purwanto. 2014. Evaluasi Hasil Belajar. Yogyakarta: Pustaka Pelajar.

R.Soedjadi. 2008. Kiat Pendidikan Matematika Indonesia. (Jakarta: Dep.Pendidikan Matematika)

Sani, Ridwan Abdullah. 2016. Inovasi Pembelajaran. Jakarta : Bumi Aksara.

Slameto. 2010. Belajar dan Faktor-Faktor yang Mempengaruhinya. Jakarta:PT Rineka Cipta.

Slavin, Robert E. 2016. Cooperatif Learning “Teori, Riset, dan Praktik”. Bandung.

Soegeng.2006. Dasar-Dasar Penelitian. Semarang : IKIP PGRI PRESS.

Soegeng.2015.Filsafat Pendidikan. Yogyakarta : Magnum Pustaka Utama.

Sudjana.2005.Metode Statistika. Bandung : PT. Tarsito Bandung.

Sudjana, Nana. 2013. Penilaian Hasil Proses Belajar Mengajar. Bandung: PT Remaja Rosdakarya.

Sugiono.2010. Statistika untuk Penelitian. Bandung : Alfabeta.

Sugiyono. 2010. Metode Penelitian Pendidikan Pendekatan Kuantitatif, kualitatif, dan R\&D. Bandung: Alfabeta

Sugiyono. 2013. Metode Penelitian Pendidikan Pendekatan Kuantitatif, Kualitatif, dan R\&D. Bandung: Alfabeta.

Sugiyono. 2016. Metode Penelitian Kuantitatif, Kualitatif dan R\&D. Bandung: PT Alfabet

Sugiyono. 2017. Metode Penelitian Kuantitatif, Kualitatif, dan $R \& D$. Bandung: Alfabeta.

Sumantri M, Johar Permana, 2007. Strategi Belajar Mengajar. Jakarta: Direktorat Jendral Pendidikan Tinggi.

Sumantri. 2015. Strategi pembelajaran. Jakarta: Kharisma Putra Utama.

Suprijono,Agus. 2016. Model-Model Pembelajaran Emansipatoris. Yogyakarta: Pustaka Pelajar. 
Indonesian Journal Of Educational Research and Review, Vol. 2 No. 3, Oktober 2019

P-ISSN: 2621-4792, E-ISSN: 2621-8984

Trianto, (2007). Model-model Pembelajaran ilnovatif berorientasi kontruktivistik. Prestasi Pustaka: Jakarta.

Uno, Hamzah, Nurdin Mohamad.2011. Belajar dengan Pendekatan PAIKEM. Jakarta; Bumi Aksara 